\title{
DIALOGISMO E ALTERIDADE OU A TEORIA DA ENUNCIAÇÃO EM BAKHTIN
}

\author{
Vera Lúcia Pires
}

\begin{abstract}
RESUMO: Pour Bakhtine, le but du langage est lê dialogisme, cette relation avec l'autre. La vie est dialogique par nature. Vivre signifie participer à un dialogue (Bakhtin, 1961: 293). Tout ce qui me concerne vient du monde extérieur par le biais de la parole de l'autre. Tout énoncé est le maillon d'une chaîne infinie d'énoncés, un carrefour d'opinions et de visions du monde. Dans ce réseau dialogique qu'est le discours, s'instaurent des significations don't l'orige n'est pas le moment de l'enonciation, mais font parties d'un continuum. Autrement dit, l'individu n'est pas l'origine de ce qu'il dit.
\end{abstract}

PALAVRAS-CHAVE: discurso, dialogismo, intersubjetividade, sentido.

\section{INTRODUÇAO}

Se no início do século $\mathrm{XX}$, a lingüística tradicional referendava a filosofia humanista clássica, encarando o estudo da língua como representação evidente e objetiva do real, outra era a visão de Mikhail Bakhtin.

Vera Lúcia Pires é professora da Universidade Federal de Santa Maria. 
Precursor do que, muitas décadas depois, Berman (1982) nomeou de humanismo moderno ${ }^{1}$, o pensador russo considerava a relação sócio-histórica e dialógica entre sujeitos o cerne do processo de constituição do discurso, priorizando a intersubjetividade em detrimento à representação objetiva da realidade.

O filólogo Bakhtin fundou, a partir de 1919, um círculo multidisciplinar de estudos, integrado por filósofos, poetas, cientistas, críticos de arte e literatura, escritores e músicos que discutiam as questões relevantes para as ciências sociais, norteados pela concepção de que a linguagem não deveria ser somente um objeto de estudo da ciência lingüística, mas deveria ser vista como uma realidade definidora da própria condição humana. O Círculo de Bakhtin teve uma intensa produção escrita entre 1920 e 1929, a partir daí, com os expurgos políticos, vários membros do círculo desapareceram e Bakhtin passou a trabalhar sozinho e em silêncio, ele mesmo exilado na Sibéria.

Em meados da década de 60, Bakhtin tornou-se conhecido na Europa ocidental e, a partir de então, no resto do mundo. Tal reconhecimento deu-se por intermédio de J. Kristeva que, trabalhando no domínio dos estudos literários, via na teoria polifônica do filólogo russo uma forma de reação contra a submissão do sujeito pelas estruturas, pelo viés da história.

A importância da obra de Bakhtin não alcançou somente a teoria literária, senão toda a lingüística. Seus trabalhos foram relevantes para a compreensão de como se efetua a produção da significação no funcionamento dos discursos da vida cotidiana, aqueles que se relacionam diretamente com a situação em que são produzidos, identificando-se neles, mais facilmente, a natureza social da linguagem. Para ele, a linguagem é uma prática social cotidiana que envolve a experiência do relacionamento entre sujeitos. Essa experiência é parte integrante do sentido do dizer.

Já no final dos anos vinte, o autor defendia a necessidade de uma teoria lingüística da enunciação como único meio de dar conta da compreensão real das formas sintáticas. Em sua opinião, as análises sintáticas dos elementos do discurso constituem análises do corpo vivo da enunciação (pois) as formas sintáticas são as que mais se aproximam das formas concretas da enunciação, além de estarem ligadas às condições reais da fala (BAKHTIN, 1929, p. 139). A partir de então, ele passou a estudar as formas sintáticas que representavam, no interior de um discurso, o discurso de outros via discurso relatado e suas variantes.

Antecedendo em décadas certas reflexões das teorias modernas da

${ }^{1}$ Segundo Berman, o eixo do humanismo moderno é a cultura do diálogo e o estudo do cotidiano. 
linguagem, o filólogo russo pregava a necessidade de se encontrar um elo entre a forma material exterior e o elemento semântico-ideológico interior que os mantivesse em equilíbrio. Nesse sentido, criticou quem pregava a exclusividade de um dos elementos em detrimento do outro: o formalismo contra o ideologismo (conteudismo). O elemento de ligação entre a forma e o sentido seria, no entender de Todorov (1981), a enunciação. Ao trabalhar a enunciação como substância da língua, Bakhtin superou a dicotomia forma-conteúdo e integrou a experiência social à organização lingüística.

Nosso interesse na teoria bakhtiniana da enunciação recorta conteúdos pertinentes à palavra como signo dialético e ideológico, ao princípio dialógico, à alteridade e aos discursos cotidianos. Ao integrar esses elementos, julgamos contribuir para a construção de uma análise discursiva que assuma o movimento dialógico em direção à alteridade. Um movimento de busca e de reconhecimento de si mesmo por intermédio da relação solidária com os outros.

\section{O MOVIMENTO DA LINGUAGEM Aं ENUNCIAÇÃO}

A linguagem, para Bakhtin, é uma prática social que tem na língua a sua realidade material. A língua é entendida não como um sistema abstrato de formas lingüísticas à parte da atividade do falante, mas como um processo de evolução ininterrupto, constituído pelo fenômeno social da interação verbal, realizada através da enunciação, que é a sua verdadeira substância (BAKHTIN, 1929, p. 127). Diferentemente de Saussure e de seu objetivismo abstrato, o autor russo valorizava a fala, que não é individual, senão social e está estreitamente ligada à enunciação, já que o momento da enunciação, instaurando a intersubjetividade, instaura também a interação.

Defendendo a natureza social e não individual da linguagem, ele situou a sua realidade material - língua -, bem como aos indivíduos que a usam, em um contexto sócio-histórico. A língua penetra na vida através dos enunciados concretos que a realizam (BAKHTIN, 1979², p. 282), da mesma forma que, através deles, a vida penetra nela. Ao veicular concepções de mundo, a linguagem torna-se um lugar de confrontos ideológicos. A palavra é o fenômeno ideológico por excelência, pois carrega uma carga de valores culturais que expressam as divergências de opiniões e as contradições da sociedade, tornando-se assim um palco de conflitos. Ela, no en-

${ }^{2}$ As referências concentram-se nos textos: $O$ problema dos gêneros do discurso, originais de 1952/53 e O problema do texto nas áreas da lingüística, da filologia, das ciências humanas. Tentativa de uma análise filosófica, originais de 1959/61. 
tanto, não pertence a ninguém, estando a serviço de qualquer ser humano e de qualquer juízo de valor.

Na realidade, não são palavras o que pronunciamos ou escutamos, mas verdades ou mentiras, coisas boas ou más, importantes ou triviais, agradáveis ou desagradáveis, etc. A palavra está sempre carregada de um conteúdo ou de um sentido ideológico ou vivencial. É assim que compreendemos as palavras e somente reagimos àquelas que despertam em nós ressonâncias ideológicas ou concernentes à vida. (BAKHTIN, 1929, p. 95)

O signo lingüístico tem, pois, uma plurivalência social que se refere ao seu valor contextual. $\mathrm{O}$ fato de diferentes grupos sociais empregarem o mesmo sistema lingüístico faz com que as palavras manifestem valores ideológicos contraditórios, tendo o seu sentido firmado pelo contexto em que ocorrem. É a situação social imediata a responsável pelo sentido.

Outra característica do signo bakhtiniano, ligada à anterior, é a mutabilidade, uma vez que, como reflexo das condições do meio social, a palavra é sensível às transformações na estrutura social, registrando todas as mudanças. As palavras estão presentes em todas as relações sociais e são tecidas a partir de uma infinidade de fios ideológicos, portanto serão sempre o indicador mais sensivel de todas as transformações sociais (BAKHTIN, Ibid., p. 41).

Inovando todos os estudos sobre a questão da pluralidade semântica das palavras nos discursos, Bakhtin $\left(1963^{3}\right.$, p. 263) analisou a vida da palavra, sua passagem de um locutor a outro, de um contexto a outro, de uma coletividade social, de uma geração a outra, e as via como unidade migratória entre discursos, sem desvincularem-se jamais de seu trajeto interdiscursivo anterior.

O verdadeiro interesse do autor, no entanto, não era o sistema, mas a linguagem enquanto uso e em interação social. E a enunciação seria, precisamente, o momento do uso da linguagem, processo que envolve não apenas a presença física de seus participantes como também o tempo histórico e o espaço social de interação. Sua crítica à lingüística, enquanto teoria da abstração - língua -, foi sempre nesse sentido, o de faltar a ela uma abordagem da enunciação, que desse conta do que, no seu entender, era o discurso, ou seja, a linguagem em sua totalidade concreta e viva (BAKHTIN, 1963, p. 181).

O objeto de estudo do autor está, parece-nos, claramente definido: é a enunciação, não apenas como realidade da linguagem, mas também como estrutura sócio-ideológica. A enunciação não parte de um sujeito

${ }^{3}$ Trabalhamos com a edição modificada da original de 1929, em sua tradução para o inglês. 
individual, considerado isoladamente, mas é produto da interação de dois indivíduos socialmente organizados e do contexto da situação social complexa em que aparece (BAKHTIN, 1927 e 1929).

Demarcando a enunciação como marca de um processo de interação entre sujeitos, uma vez que a palavra tem duas faces, isto é, parte de alguém com destino a outro alguém, Bakhtin instituiu o princípio dialógico para o estudo de seu objeto.

\section{A ENUNCIACAAO COMO PRINCÍPIO DIALÓGICO}

A base do princípio dialógico é a filosofia do diálogo ou da relação ${ }^{4}$, de M. Buber, que, afirmando a palavra como dialógica, estabelece a relação "entre" os seres humanos e funda a experiência da intersecção, ou interação. Para essa filosofia, o homem não é um ser individual, mas uma relação dialógica entre eu-tu. O "tu" é condição de existência do "eu", pois a realidade do homem é a realidade da diferença entre um "eu" e um "tu". $\mathrm{O}$ "eu" não existe individualmente, senão como abertura para o outro. Origina-se aí a constituição do par fundador - eu-outro.

Para Bakhtin, o fundamento de toda a linguagem é o dialogismo, essa relação com o outro. A vida é dialógica por natureza. Viver significa participar de um diálogo (BAKHTIN, 1961, p.293). Tudo o que me diz respeito vem-me do mundo exterior por meio da palavra do outro. Todo enunciado é apenas um elo de uma cadeia infinita de enunciados, um ponto de encontro de opiniões e visões de mundo. Nessa rede dialógica que é o discurso $^{5}$, instituem-se sentidos que não são originários do momento da enunciação, mas que fazem parte de um continuum. Um locutor não é o Adão bíblico, perante objetos virgens, ainda não designados, os quais ele é o primeiro a nomear (Bakhtin, 1979, p.319). Dito de outra maneira, o indivíduo não é a origem de seu dizer.

Dessa forma, é necessário pensar sempre no homem em relação aos (e com) outros homens e afirmar que o indivíduo é social e somente constitui-se verdadeiramente humano na relação viva, ou seja, cotidiana e social, com os outros seres humanos, uma vez que a experiência verbal individual do homem toma forma e evolui sob o efeito da interação contínua e

\footnotetext{
${ }^{4}$ Um dos principais representantes da filosofia do diálogo foi o filósofo austríaco Martin Buber, citado por Todorov (1981) como influência para o pensamento de Bakhtin sobre dialogismo. A principal obra de Buber, Ich und $d u$, foi publicada em 1923. Traduzida no Brasil em 1977, pela Editora Moraes, com o nome Eu e tu.

${ }^{5}$ Bakhtin utiliza, em geral indistintamente, enunciado ou discurso. Como fazemos distinção entre esses conceitos, convencionamos que, neste trabalho, os enunciados são tratados como partes de um discurso.
} 
permanente com os enunciados individuais do outro (BAKHTIN, 1979, p.313). O fenômeno social da interação é, repetimos, a realidade fundamental da linguagem, realizando-se como uma troca de enunciados, na dimensão de um diálogo e através da enunciação (BAKHTIN, 1929, 1930 e 1979).

É importante atentar para o significado de diálogo em Bakhtin como um princípio geral da linguagem, de comunhão solidária e coletiva, mas sem passividade e não apenas como a comunicação ou a troca de opiniões vis-à-vis entre parceiros. Também é preciso frisar que o grande mérito de Bakhtin para os estudos do discurso foi introduzir o sujeito e seu contexto social via dialogismo interativo, trazendo com ele a história.

A enunciação é determinada pela situação social imediata e pelo meio social, sendo organizada, no que diz respeito ao seu conteúdo e significação, fora do indivíduo pelas condições extra-orgânicas do meio social. Por isso, ela é um produto da interação social (BAKHTIN, 1929, p. 121).

O sentido do enunciado é também engendrado pelas condições reais da enunciação e distribui-se entre as diversas vozes que habitam o tecido da linguagem. Estabelece-se, assim, um relacionamento dialógico de sentidos entre enunciados confrontados. As relações dialógicas são relações semânticas entre todos os enunciados na comunicação verbal (BAKHTIN, 1979, p. 345).

E não poderia ser diferente, visto que a linguagem é um processo determinado pela vida social, estando em permanente evolução. É isso que faz do enunciado um continuum no fluxo incessante da interação verbal, ligado ao movimento perene da vida social e da história.

Em texto de 1926, o autor destaca que a interação social sempre se dá entre três participantes: o falante, o ouvinte e o tema do discurso, fatores que constituem esse discurso.

O discurso é como o "cenário" de um certo acontecimento. A compreensão viva do sentido global da palavra deve reproduzir esse acontecimento que é a relação recíproca dos locutores, ela deve "encená-la", se se pode dizer; aquele que decifra o sentido assume o papel de ouvinte; e, para sustentá-lo, deve igualmente compreender a posição dos outros participantes. (BAKHTIN , 1926, p.199)

A alteridade intervém sempre. A identidade é um movimento em direção ao outro, um reconhecimento de si pelo outro que tanto pode ser a sociedade como a cultura. E o elo de ligação é a linguagem. Através da palavra, defino-me em relação ao outro, em última análise, em relação à coletividade. (...) A palavra é o território comum do locutor e do interlocutor (BAKHTIN, 1929, p.113). 
O suporte do sujeito é um "nós", pois ele não coincide jamais consigo mesmo, sendo inesgotável em sua significação. Eu só pode se realizar no discurso, apoiando-se em nós (BAKHTIN, 1926, p.192). O ser humano não existe para si, senão na medida em que é para os outros. Todorov (Ibid.) lembra, sobre essa questão, que certos acontecimentos da vida de um indivíduo só são experimentados pelos outros e exemplifica: o próprio nascimento ou a morte. O que comprovaria o contínuo movimento de nossa própria vida: começar e terminar nos outros.

Estudos em torno à obra de Bakhtin tendem a dividir o dialogismo em duas formas: o diálogo entre interlocutores, baseado na interação fundadora da linguagem, e a relação entre discursos, chamada polifonia, ou seja, as vozes exteriores que marcam nosso discurso ${ }^{6}$.

O nome dialogismo é mantido em relação à interação entre sujeitos por ser o próprio princípio constituidor da vida e do social. A relação intersubjetiva, estabelecida pela enunciação, constrói tanto os sujeitos quanto os sentidos do discurso.

Quanto ao diálogo entre discursos, o que produzimos é um tecido de vozes, de muitas vozes que se relacionam polemicamente entre si, resolvendo a relação no interior mesmo dessa tessitura. De onde podemos concluir que o sujeito é dialógico por natureza e seu discurso é polifônico.

No entender de Pessoa de Barros (1994), a polifonia é uma relação entre textos, que manifesta as vozes componentes de nosso discurso. Nos textos polifônicos, o diálogo entre discursos é marcado, enquanto que nos monofônicos há um efeito de sentido que dissimula o dialogismo fundador. Entretanto, mesmo que tentássemos ocultar as vozes, o dialogismo como constitutivo da linguagem permaneceria e o texto ou o discurso faria enxergar a comunidade e a história.

O estabelecimento da relação eu-tu, que emerge da concepção dialógica, deve ser entendido como um deslocamento do conceito de sujeito. O sujeito centrado é substituido pelas diferentes vozes sociais que o tornam um sujeito histórico e ideológico. Concordamos com a tese de pesquisadores brasileiros da obra de Bakhtin, como Pessoa de Barros, 1994 e Dahlet, 1997, no sentido de que sua concepção de dialogismo, pioneiramente, abala a concepção clássica do sujeito cartesiano uno, uma vez que o sujeito bakhtiniano torna-se solidário às vozes, às alteridades de seu discurso. Em Bakhtin, a intersubjetividade é anterior à subjetividade, uma vez que o pensamento, enquanto pensamento, nasce no pensamento do outro (BAKHTIN, 19797 , p. 329). E a enunciação como uma experiência

${ }^{6}$ Distingue-se da polifonia a intertextualidade, termo cunhado por J. Kristeva e que faz referência explícita a outros textos.

${ }^{7}$ Referências relativas ao texto Gêneros do discurso, escrito originalmente entre 1952 e 1953. 
social, dialógica, ativa e interativa passa a ser o centro da interlocução.

DO DIALOGISMO A ALTERIDADE

O princípio dialógico funda a alteridade como constituinte do ser humano e de seus discursos. Reconhecer a dialogia é encarar a diferença, uma vez que é a palavra do outro que nos traz o mundo exterior.

Nossa fala, isto é, nossos enunciados (...) estão repletos de palavras dos outros. (Elas) introduzem sua própria expressividade, seu tom valorativo, que assimilamos, reestruturamos, modificamos. (...) Em todo o enunciado, contanto que o examinemos com apuro, (...) descobriremos as palavras do outro ocultas ou semi-ocultas, e com graus diferentes de alteridade. (BAKHTIN, 1979, p. .314/318)

Ao produzirmos discursos, não somos a fonte deles, porém intermediários que dialogam e polemizam com os outros discursos existentes em nossa sociedade, em nossa cultura. Como já foi dito, a relação dialógica é polêmica, não há passividade. Nela, o discurso é um jogo, é movimento, tentativa de transformação e mesmo subversão dos sentidos. O sentido de um discurso jamais é o último: a interpretação é infinita. O que faz evoluir um diálogo entre enunciados é essa possibilidade sem fim de sentidos esquecidos que voltam à memória, provocando neles a renovação dentro de outros contextos.

Conforme Todorov (ibid.), Bakhtin esboçou uma nova interpretação da cultura que a coloca como uma composição de discursos que retêm a memória coletiva e em relação aos quais é necessária uma tomada de posição. É essa interação dialógica e opinante que gera movimento e transformações, afastando do sujeito o assujeitamento.

Derivado do princípio da relação dialógica polêmica, estabelecido pelo sujeito produtor de discursos em um contexto social, Bakhtin instituiu um método para seu trabalho que, segundo Todorov (Ibid.), seria a interpretação ou a compreensão responsiva ativa.

Toda compreensão é um processo ativo e dialógico, portanto tenso, que traz em seu cerne uma resposta, já que implica sujeitos. O ser humano, juntamente com seu discurso, sempre presume destinatários e suas respostas. A compreensão de um enunciado vivo é sempre prenhe de respostas (BAKHTIN, 1979). A cada palavra da enunciação que estamos em processo de compreender, fazemos corresponder uma série de palavras nossas, formando uma réplica. (BAKHTIN, 1929, p.132). O sujeito que produz um discurso não quer uma compreensão passiva que somente levaria à repetição de seu pensamento, mas almeja respostas que evidenciem 
adesão, concordância ou, contrariamente, objeção às idéias expostas. $\mathrm{O}$ sujeito bakhtiniano gera respostas, toma atitudes, constituindo-se um sujeito não totalmente interpelado.

Mesmo o enunciado, essa unidade concreta produzida pelo ato enunciativo, foi definido por Bakhtin (1930 e 1979) como uma expressão lingüística orientada para o outro. Assim, a construção de um discurso levaria em consideração a representação que um sujeito tem de seu destinatário, bem como a ressonância dialógica produzida por seus enunciados já proferidos e todos os enunciados de outros sobre o mesmo assunto, retidos em sua memória. Ter um destinatário, dirigir-se a alguém, é uma particularidade constitutiva do enunciado (BAKHTIN, 1979, p. 325).

Essa "responsividade" implica um juízo de valor que, partindo da relação do enunciado com a realidade, com seu autor e com os outros enunciados anteriores, traz para o discurso os elementos ideológicos que o constituem. Todo enunciado (discurso, conferência, etc.) é concebido em função de um ouvinte, ou seja de sua compreensão e de sua resposta, bem como de sua percepção avaliativa (concordância ou discordância) (BAKHTIN, 1930, p. 292).

Faz parte da "orientação social" do enunciado em direção a um outro sujeito colocar em evidência a questão dos valores, que também é uma questão ideológica. Viver significa ocupar uma posição de valores em cada um dos aspectos da vida (BAKHTIN, 1979, p. 201), já que as categorias fundamentais de valores são o eu e o outro.

Da parte do autor do enunciado, esse avaliará seu destinatário e por aí modelará a forma e o modo de produção de seus enunciados, que serão diversos conforme a situação social e a importância de seu interlocutor, bem como suas posições, conviç̧ões e pontos de vista.

É no enunciado que se dá o contato entre a língua e a realidade. A escolha das palavras para a construção de um enunciado leva em conta outros enunciados de outros sujeitos, em relação aos quais o locutor se posiciona. Assim, quando reproduzimos o discurso do outro, nele podemos captar uma dupla expressão: a original, do outro e a expressão atualizada que é por nós introduzida no enunciado do qual vai fazer parte. (BAKHTIN, Ibid.).

Em conseqüência, não só ao locutor cabem os direitos sobre as palavras, mas também ao ouvinte e a todos cujas vozes são ouvidas naquele discurso. A palavra é um drama com três personagens que é representado fora do autor. Por isso o processo de compreensão do enunciado foi visto por Bakhtin como uma relação que envolvia os participantes e onde quem compreende torna-se o terceiro no "diálogo". O primeiro é o locutor, o 
segundo é o destinatário próximo, de quem se espera uma compreensão responsiva, e o terceiro é o superdestinatário superior, de quem o locutor prevê uma compreensão responsiva ideal e que pode adquirir, dependendo da época, uma identidade concreta viável (Deus, a verdade absoluta, o julgamento da consciência humana imparcial, o povo, o julgamento da história, a ciência etc. (BAKHTIN, Ibid. p. 356), porque para todo discurso é imprescindível uma resposta. Na busca pela compreensão, o discurso vai longe, torna-se um elo, entra em um diálogo onde o sentido, além de não ter mais fim, contém toda a memória coletiva do dizer.

De fato, para Bakhtin a produção do discurso envolvia um trio, composto pelo autor, pelo destinatário e por todas as vozes-outras que sempre-já nele habitavam, pois o "diálogo" é o acontecimento do encontro e interação com a palavra do(s) outro(s). A alteridade é, para o autor, um processo dialógico em que o elemento comum é o discurso.

O DISCURSO COTIDIANO COMO POSSIBILIDADE DE ACONTECIMENTO

A importância do estudo dos discursos cotidianos, ou os gêneros da vida cotidiana, foi enfatizada em toda a obra de Bakhtin. Em tais discursos, a natureza social da linguagem é diretamente percebida, pois é visível a relação entre o enunciado e o meio social circundante. Situação de enunciação, ou seja, o contexto extraverbal, as condições sociais reais, e enunciado são essenciais um ao outro, já que de sua união depende seus sentidos. A realidade faz parte do sentido.

Ao afirmar que a forma do enunciado, seu estilo e composição, é determinada pela relação de valor que o locutor estabelece com a realidade representada no discurso, Bakhtin (1926) indagava sobre como dar-seia esse processo de representação do discurso com a situação extra-verbal que o engendra.

A resposta à indagação foi o emprego de um método de análise que comportava o contexto extraverbal que, para o autor russo, seria composto por três aspectos: o horizonte espacial - espaço e tempo - comum aos interlocutores; o conhecimento e compreensão da situação, ou seja, o saber comum, o conteúdo temático partilhado; e a avaliação (elemento axiológico) que manifesta a posição dos sujeitos frente à situação vivenciada. A situação integra-se ao enunciado como um elemento indispensável à sua constituição semântica (BAKHTIN, 1926, p.190). O elemento extraverbal liga-se ao verbal, o não dito determina o dito. Eis a causa de diferentes situações determinarem diferentes sentidos de uma 
mesma expressão verbal.

Decorrente do fator abordado anteriormente, outro ponto foi considerado essencial no discurso cotidiano: a interação que une os participantes de uma mesma situação e que os faz dividirem uma unidade de condições reais de vida, tornando-os solidários e levando-os a apoiar a intersubjetividade verbal em um "nós" discursivo. A solidariedade existe entre interlocutores, qualquer que seja seu número. Quanto mais amplo o horizonte comum dos interlocutores, mais os enunciados deverão se apoiar em elementos da vida que sejam constantes e estáveis e em avaliações sociais essenciais e fundamentais (BAKHTIN, Ibid., p.192).

Bakhtin alertava, com isso, para o fato de muitas avaliações sociais fundamentais não precisarem ser explicitadas verbalmente, por pertencerem ao contexto situacional comum ao grupo social ou, até mesmo, à cultura. Tais avaliações, condicionadas pela cultura coletiva, ressoam sempre, organizando ações e condutas de todas as pessoas e tornando-se um dogma indiscutível, pertencente à memória histórico-coletiva de uma sociedade.

Contudo, como a avaliação passa sempre pela questão ideológica da representação de visões de mundo, institui-se no interior do discurso um jogo dramático de vozes, estabelecendo uma tensão dialética. Como os enunciados são, comumente, impregnados de subentendidos e não ditos, qualquer que seja o sentido corrente ou a significação do discurso cotidiano, não há coincidência plena com sua constituição puramente verbal.

Assim sendo, a possibilidade de um trabalho de sentidos nos enunciados pode transgredir e subverter sentidos arraigados e instaurar outros. O enunciado, como nos fez ver Bakhtin (1979), não é puro reflexo do que existe fora dele. Ele sempre cria algo que, antes de seu acontecimento, não existia, algo novo e irreproduzível relacionado ao elemento axiológico. Dialeticamente, entretanto,

qualquer coisa criada se cria sempre a partir de uma coisa que é dada (a língua, o fenômeno observado na realidade, o sentimento vivido, o próprio sujeito falante, o que é já concluído em sua visão do mundo, etc.). O dado se transfigura no criado (BAKHTIN, 1979, p. 348).

O sujeito-autor do enunciado produz, ao construí-lo, um acontecimento lingüístico, pois ainda que se veja, em todo enunciado, o sistema da língua, responsável pelo que é repetitivo e reproduzível, ao mesmo tempo, cada enunciado é único e irreproduzivel, sendo nisso que reside seu senti$d o$. Mesmo havendo uma tentativa de reprodução, releitura e até citação, o enunciado será uma recriação, uma singularidade, visto que produzido por um outro sujeito, em um outro momento. $O$ acontecimento na vida do 
texto, seu ser autêntico, sempre sucede nas fronteiras de duas consciências, de dois sujeitos (BAKHTIN, Ibid., p.333).

$\mathrm{O}$ enunciado manifesta a história do pensamento em direção ao pensamento e ao sentido dos outros. Quanto ao sentido, que integra o enunciado enquanto seu valor semântico, ele está também ligado à história através do ato único de sua realização. Segundo Bakhtin (1963), o discurso é a linguagem em sua totalidade concreta e viva. Os enunciados dele fazem parte, sendo considerados produtos de um processo ativo do qual o sistema lingüístico convencional, enquanto ordem sintática e lexical repetível, é um dos elementos; o outro é tudo o que fornece ao enunciado o fato de sua enunciação, o que significa, também, um contexto histórico, social, cultural, etc., único (TODOROV, 1981, p. 44). O contexto de enunciação, como instância do discurso, é também um acontecimento que integra o horizonte social comum dos sujeitos. O contexto e a história refletem-se no sentido do enunciado, integrando-o e fazendo dos discursos do cotidiano um acontecimento.

Um último comentário a respeito dos discursos da vida cotidiana, referente ao texto sobre os gêneros do discurso: Bakhtin (1979) os via como os mais livres e criativos por fazerem parte da intimidade social. O gênero é entendido como a forma padrão e relativamente estável de estruturação de um todo que compõe os enunciados produzidos por um sujeito. As variações percebidas nos diferentes gêneros decorrem em conformidade às circunstâncias, à posição social e ao relacionamento dos interlocutores do discurso. Dessas condições sempre diferenciadas e únicas, deriva a singularidade do enunciado que, apesar disso, não é uma combinação absolutamente livre dos signos da língua, manifestando uma vontade individual. Nossa escolha será, de certa maneira, condicionada pelo contexto histórico-social. Os gêneros são exatamente os enunciados devidamente organizados em função das possibilidades - ou dos campos de atividade humana - do processo discursivo.

Enfim, os gêneros aparecem como tipos de discursos, utilizados conforme a realidade situacional em que o discurso é produzido e os sujeitos envolvidos.

Os discursos do cotidiano caracterizam-se por esse estreito e íntimo encontro com o outro e com a situação vivenciada, em nível de igualdade entre os sujeitos, o que os torna um campo privilegiado para o estudo da relação entre os parceiros discursivos, de sua relação com o próprio mundo e da constituição das heterogeneidades de seus discursos. $\mathrm{O}$ fato de neles melhor se observar a importância da situação extraverbal para a constituição do sentido, facilita a percepção e a apreensão de aconteci- 
mentos discursivos, pois, sendo a palavra o indicador mais sensivel de todas as transformações sociais em todas as épocas, foi através desses discursos cotidianos que se detectaram as mudanças de sentidos que apontavam para a destruição de visões de mundo tradicionais e sedimentadas.

Uma mesma língua, afirmou Bakhtin $\left(1975^{8}\right)$, é (co)habitada por falares diversos, linguagens sociais dinâmicas que se cruzam, atravessadas pelo social e pela história. São linguagens do plurilingüismo em que estão inscritos pontos de vista inseparáveis das transformações da experiência cotidiana. É esse movimento dinâmico de práticas linguageiras plurais da vida cotidiana que é capaz de romper o aprisionamento do sentido no signo lingüístico, libertando-o para novos significados.

O enunciado é o objeto de estudo da linguagem, mas ele não deve ser estudado isoladamente. O momento de seu acontecimento - a enunciação -, bem como a situação social que a envolve, constitui a relação entre sujeitos, fazendo da interação social o fundamento semântico de todo o discurso. Todavia, longe de prescindir dos elementos da língua, Bakhtin integraos à sua análise enunciativa, fazendo do sistema normativo o suporte para a transcendência dialógica.

A coerência do pensamento multifacetado de Bakhtin perpassa sua obra e foi expressa nas ligações que embasaram sua proposta teórica e seu método de pesquisa à sua filiação filosófica, deixando sempre claro que o importante para ele era a investigação do ser humano, social e público, em permanente relação intersubjetiva de alteridade, através da compreensão de seu discurso.

Concluindo, enfatizamos que a teoria bakhtiniana foi e continua sendo essencial para os estudos que envolvem a enunciação, pois expressa de forma clara, engajada e coerente a relação sujeito-linguagem-históriasociedade, vendo na enunciação o verdadeiro fundamento dessa relação. Em outras palavras, pela enunciação, Bakhtin recuperou o sujeito para o discurso e instituiu um processo de intersubjetividade no qual a identidade é um reconhecimento desse sujeito através do outro.

\section{BIBLIOGRAFIA}

BAKHTIN, M. (1927) Freudism. Nova York: Academic Press, 1976. . (1926) Le discours dans la vie et dans la poésie. In: TODOROV, T. Mikhaïl Bakhtine: le principe dialogique. Paris: Éditions du Seuil, 1981.

${ }^{8}$ Os originais foram escritos entre 1934 e 1935. 
. (1930) La structure de l'énoncé. In: TODOROV, T. Mikhaïl Bakhtine: le principe dialogique. Paris: Éditions du Seuil, 1981.

. (1963) Problemas da poética de Dostoievski. Rio de Janeiro: Forense Universitária, 1981.

. (VOLOCHÍNOV) (1929) Marxismo e filosofia da linguagem. 3. ed. São Paulo: Hucitec, 1986.

. (1961) Towards a reworking of the Dostoievsky book. In: Problems of Dostoievsky's poetics. 3. ed. Minneapolis: University of Minnesota Press, 1987.

. (1963) Problems of Dostoievsky's poetics. (1963) 3. ed. Minneapolis: University of Minnesota Press, 1987.

. (1975) Questões de literature e estética: a teoria do romance. São Paulo: Hucitec, 1988.

. (1979) Estética da criação verbal. 2. ed. São Paulo: Martins Fontes, 1997. 